\title{
Correspondence
}

\section{Orbital rhabdomyosarcoma}

\section{To the Editorial Committee of the British Journal of Ophthalmology}

SIRS,-Concerning the article, "Orbital Rhabdomyosarcoma in an Infant" by G. C. Sood, D. K. $\overrightarrow{\vec{\omega}}$ Sen, R. Diwan, and A. L. Aurora (British Journal of Ophthalmology, 1970, 54, 203), I should like to bring to your attention our recent pubfications concerning the role of radiation therapy in the $\frac{0}{0}$ management of this disease. It is apparent that our experience differs from that of Dr. Lederman ir and it is our belief that radiation therapy should become the treatment of choice in this disease. 0 The reasons for our differing experience remain obscure. I can add that current evaluation of the $\mathcal{E}_{\mathrm{O}}$ .. originally reported patients, and subsequent experience, serve only to confirm our impression.

$$
\text { Yours faithfully, }
$$

Robert H. SAgerman

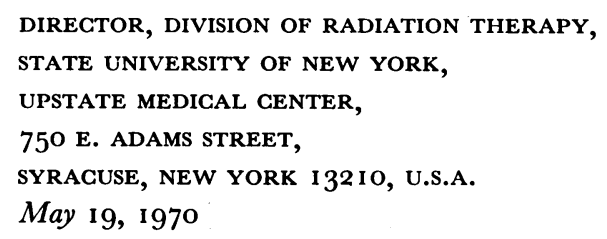

\section{References}

CASSADY, J. R., SAgerman, R. H., TRetTer, P., and Ellsworth, R. M. (I968) Radiology, 91, I 16

Sagerman, R. H., Cassady, J. R., and tretter, P. (ig68) Trans. Amer. Acad. Ophthal. Otolaryng., 72, 849

\section{Book reviews}

Ophthalmic Genetics. By A. SorsBy. 2nd ed., 1970. Pp. 269, 235 figs, bibl. Butterworth, London. (I I Os.)

This second edition of Prof. Arnold Sorsby's "Genetics in Ophthalmology", originally published in N I95I, has been almost completely rewritten and can be considered a new book on this subject. It is arranged in three sections: the globe as a whole, individual tissues, and generalized disorders with ocular aspects.

This is a concise and eminently readable textbook of ophthalmic genetics and as such is unequalled. There are several typographical errors in the text, certain of the terminology is oldfashioned or even incorrect (choroidal sarcoma, p. 5), and a few statements are confusing, controversial, or inaccurate. Retinal aplasia is used as the name for a specific entity (Alström and Olson) 
and also for certain of the atypical forms of retinitis pigmentosa; this is confusing. Haldane's interpretation of dominant partial sex-linkage for a family with retinitis pigmentosa hardly merits mention; transmission appears to be autosomal dominant. Ichthyosis is said generally to be recessive, yet autosomal dominant transmission is the most common with autosomal recessive transmission being distinctly uncommon. Despite these minor criticisms this book can be recommended to all ophthalmologists as an excellent readable manual on this important subject.

Manual of Refraction. By A. E. Slonne. 2nd ed., i970. Pp. 282, 54 figs, bibl. Little Brown, Boston; Churchill, London. (I I Os.)

This second edition of the "Outlines of Refraction" is similar in form to the first, but new chapters on streak retinoscopy and recent trends in refraction have been added. The book, based on lecture notes in refraction given to post-graduate students, sustains its original elementary approach to the problems of refraction which it presents in a clinical form. The optical principles underlying the practice of refraction are not dealt with in great depth and only a very small amount of mathematics is displayed.

The book is easily and quickly read and may serve to augment clinical aspects of refraction not covered fully by more comprehensive text-books, although the expense probably will outweigh these debatable advantages.

Ultrasonography in Ophthalmology. By J. Vanýsek, J. Preisovä, and J. Obraz. 1970. Pp. 222, I 00 figs, bibl. Czechoslovak Medical Press, Prague; Butterworths, London. (76s.)

This is a review of 8 years' experience of a group of pioneers in this new field. The first part of the book is devoted to the physical properties of ultrasound and the instrumentation for its use in ophthalmology. The average clinician will be flattered by the authors' assumption that this will be readily intelligible to him, but it does at least emphasize that there is more to the subject than mere bat-squeak echography.

The clinical section occupies half the book, but it is expanded by case histories and illustrations of echograms so that the amount of clinical material is less than may be apparent at first sight. It is apparent that most of the work has been carried out by the A-scan method. Emphasis is placed on the investigation of ocular tumours, retinal detachment, intra-ocular foreign bodies, and ocular measurement. There is a section on the more difficult technique of studying orbital lesions.

Ultrasonography is a very new technique but its potentials in some fields, as in eyes with opaque media, have always been obvious, In most of the cases cited by the authors it would seem that the investigation offered little more information than could be obtained by well-established methods. A feature of note is the possibility of relating a foreign body to the walls of the globe, thus showing whether it is extra- or intra-ocular. More diagnostic accuracy may be expected, although the authors have added a note of caution in that ultrasound is potentially damaging to tissues. A theoretical possibility of great potential is that the nature of a tissue may be predicted from its reflecting properties to various wavelengths of ultrasound.

The Vitreous in Clinical Ophthalmology. By N. S. JAFfe. I $\quad$ 1969. Pp. 3 I 0,334 figs (some col.), bibl. Mosby, St Louis; Kimpton, London. (292s.)

This book is written by a clinician seeking to explain clinical observations by applying factual knowledge and hypotheses to the behaviour of a tissue about which little was known before the introduction of the newer methods of examination. The author is to be congratulated on gathering an extensive bibliography dealing with current concepts of the normal vitreous, the part it plays in producing complications after lens extraction, and its role in retinal detachment, diabetic retinopathy, 